\title{
Study on the relationship between the gray value of the image in the vicinity of the weld pool and the instantaneous voltage in $\mathrm{CO}_{2}$ welding
}

\author{
Xiao-Gang Liu ${ }^{1,2}$, Tian-Yuan Liu $^{1, a,{ }^{\dagger}}$ and Shi Huang ${ }^{1}$ \\ 1. Department of Mechanical Engineering, Guangxi University of Science and \\ Technology, Guangxi Liuzhou 545000, China \\ Department of Mechanical Engineering, Guilin University of Aerospace \\ Technology, Guangxi Guilin 541000,China \\ a707837094@qq.com
}

\begin{abstract}
Since the region near the $\mathrm{CO}_{2}$ welding of short circuiting transfer process of weld pool of light intensity changes, seriously affect the real-time and reliability of weld seam feature extraction, the application and development of $\mathrm{CO}_{2}$ welding seam tracking technology based on vision has been severely restricted. The change of instantaneous voltage can reflect the arc length changes very well and reflect changes in the strength of the arc. Numerical models were established between the gray value of the image captured by the CCD camera and the instantaneous voltage in the $\mathrm{CO}_{2}$ welding process, and the systematic study and analysis of the relative change between the two. Experimental results show that: in the short circuit phase, with the decrease of the instantaneous voltage, image average gray value decreases. At the open circuit stage, instantaneous voltage is greater than $12.3854 \mathrm{~V}$, with the increase of voltage, increasing average gray value of image; when the instantaneous voltage between $6.7708 \mathrm{~V}$ to $12.3854 \mathrm{~V}$, as the voltage increases, the average gray value of the image is reduced; when the instantaneous voltage is less than $6.7708 \mathrm{~V}$, with the increase of voltage, increasing average gray value of image.
\end{abstract}

Keywords: $\mathrm{CO}_{2}$ welding, Gray value; Instantaneous voltage

\section{Foreword}

With the rapid development of modern society, people expect more and more high to the performance of the product. Due to the welding process automation and intelligence are to guarantee welding quality, improve production efficiency and an important means to improve working conditions, so the intelligent welding is the important direction of future development. $\mathrm{CO}_{2}$ gas shielded welding is $\mathrm{CO}_{2}$ as the shielding gas, the transition of droplet short-circuits transition is the main form, it has a wide application, less energy consumption, high efficiency, strong corrosion resistance and so on[1-4].For $\mathrm{CO}_{2}$ arc welding droplet short circuit transition process of molten pool area in the vicinity of the metal spatter, light intensity changes violently seriously affected the weld 
feature extraction of real-time and reliability. As a result, based on the vision of $\mathrm{CO}_{2}$ welding seam tracking technology application and development is restricted seriously [5].The welding process of instantaneous voltage change is a good way to reflect the size of the arc length and the change of melt drip and reflect the change of arc strength finally directly affects the CCD camera to obtain the image gray value in the vicinity of molten pool, and the change of the image gray value can reflect the welding quality. Therefore, it is significant to study the relationship between the gray value of the image and the instantaneous voltage of the welding process. Aiming at the instantaneous change of arc voltage in welding process, the quality of the image is affected, and the relevant scholars at home and abroad mainly solve the two aspects. With laser stroboscopic camera to get a clear image of welding area and using CCD camera and optical filter and through the software algorithm to deal with to get a clear image [6-8].In view of these two methods have high cost, complicated operation, heavy workload, narrow range of application characteristics and do not have the essentially to grasp the changes of arc. So this paper studies the influence of the instantaneous voltage change of the welding process on the image gray value, which can be used to prepare the high quality image and lay the theoretical foundation for the welding seam automatic tracking technology.

\section{Machine Vision Image Acquisition System}

$\mathrm{CO}_{2}$ welding visual image acquisition system development for decades, the gathering principle unchanged,the overall structure changed a little,just constantly upgrade the system hardware application ability,this is because the industrial PC microprocessor by 4 before upgrading to a 64 - bit,greatly improve the processing speed.At the same time, it is precisely because of the development of the hardware technology, it makes the current real-time and reliability of the automatic welding seam tracking technology has become possible.

The principle of machine vision image acquisition system is shown in Fig1.CCD camera fixed in the direction perpendicular to the traveling direction of the torch,the torch and base metal perpendicular to each other.During the welding process, the image of the area near the weld pool is collected by the CCD camera and then passed to the industrial computer to convert to digital image.At the same time,the real-time data of voltage and current are passed through the sensor to the industrial control computer.The main part of the system hardware can be seen from the Fig1:welding torch,running gear,CCD camera,sensors and industrial control computer. 


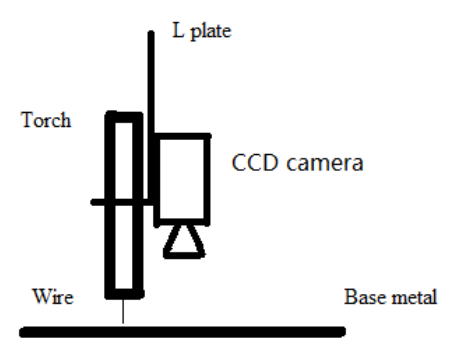

Fig. 1. Machine vision image acquisition system

\section{Relationship between Image Gray Value and Instantaneous Voltage in the Vicinity of Weld Pool}

\subsection{Short circuit transition process}

In the course of $\mathrm{CO}_{2}$ short circuit transition,the arc is generated,which is a strong heat flux from the arc column,and the molten droplet is formed at the end of welding wire.Subsequently, the droplet volume increases gradually, the heat of the arc and droplet radiation increases, the signal of the CCD camera is enhanced,and the gray value of the image is increased.A short circuit is formed by the contact between the droplet and the molten pool, the current is increased,the magnetic force is generated, and the droplet is moved in the tension itself and gravity force,and the contact surface of the droplet and the base material is gradually increased.At this time,molten pool in the vicinity of the radiation source is mainly thermal radiation of weld pool and CCD camera sensitive element receives the signal weakened with the increase of the short circuit current,droplet necking phenomenon produce serious vaporization rupture,the droplet into the weld pool,then current was decreased gradually,the arc voltage increased,to complete a transition.Arc is extinguished when the droplet and the pool being a short circuit.After the completion of the transition,arc ignition again.Fig.2 for short circuit transition process of instantaneous voltage waveform figure and melt dripping transition diagram.

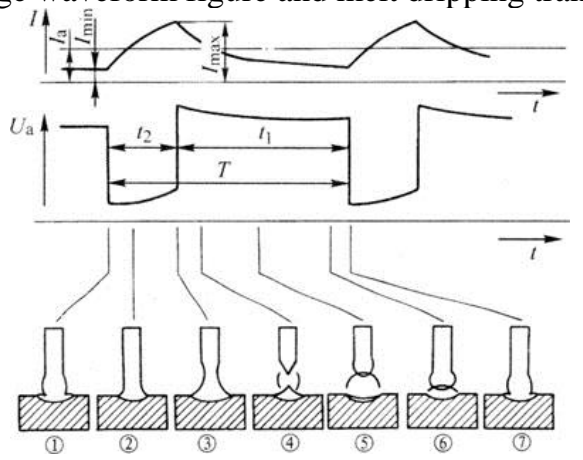

Fig. 2. Schematic diagram of instantaneous voltage waveform and droplet transfer in the process of short circuit transfer 


\subsection{Numerical relationship between image gray value and instantaneous voltage}

\subsubsection{Principle of least square method}

In many fields,a lot of test data are used to establish the mathematical model,which reflects the general variation law.The curve fitting is discrete,irregular data is used to establish the corresponding continuum model,curve fitting don't need all the data are in curve fitting, only need to test data as close as possible to the fitting curve.

In the data processing of scientific experiment,because of the error of the observed data and the quantity of the undetermined parameter $a_{i}$ is less than that of the given data points, so it is different from the interpolation problem. The discrete point $\left(x_{j}, f\left(x_{j}\right)\right), j=0,1, \cdots, m, x_{j} \in[a, b]$ is called observation data.In the specified function space $\Phi$.Find out the function approximate continuous model of $s^{*}(x) \in \Phi$ as $f$. Requirements $s^{*}$ in the $x_{j}$ value of $s^{*}\left(x_{\mathrm{j}}\right)$ and $f\left(x_{j}\right)$ error (also known as the residual error) of the square and the minimum,denoted as $\delta$.

$$
\|\delta\|_{2}^{2}=\sum_{j=0}^{m} \rho\left(x_{j}\right)\left[f\left(x_{j}\right)-s^{*}\left(x_{j}\right)\right]^{2}=\min _{s \in \Phi} \sum_{j=0}^{m} \rho\left(x_{j}\right)\left[f\left(x_{j}\right)-s\left(x_{j}\right)\right]^{2}
$$

In formula (1), $\rho\left(x_{j}\right)$ is the weight coefficient of $x_{j}$, and $\rho\left(x_{j}\right)>0(j=0,1, \cdots, m)$.Weight function can reflect the importance of different data.In order to facilitate,generally take $\rho\left(x_{j}\right)=1$. Meet the above conditions $s^{*}(x)$ called $f$ in the $m+1$ node $x_{j}(j=0,1, \cdots, m)$ on the least squares fitting curve.Literature has proved that if the linear independent group $\varphi_{0}(x), \varphi_{1}(x), \cdots, \varphi_{n}(x)$ to meet the corresponding conditions, there is only the least squares solution[9], that is $s^{*}(x)=\sum_{i=0} a_{i} \varphi_{i}(x)$. With the vector
inner product is expressed as:

$$
\left.\begin{array}{l}
\left(\varphi_{k}, \varphi_{i}\right)=\sum_{j=0}^{m} \rho\left(x_{j}\right) \varphi_{k}\left(x_{j}\right) \varphi_{i}\left(x_{j}\right) \\
\left(\varphi_{k}, f\right)=\sum_{j=0}^{m} \rho\left(x_{j}\right) \varphi_{k}\left(x_{j}\right) \varphi_{i}\left(x_{j}\right)
\end{array}\right\}(k, j=0,1 \cdots, n)
$$

Thus satisfying the square of the error and the smallest coefficient $a_{i}$ and the basis function $\varphi_{i}(x)(i=0,1, \cdots, n)$ can be determined by the following matrix: 


$$
\left(\begin{array}{cccc}
\left(\varphi_{0}, \varphi_{0}\right) & \left(\varphi_{0}, \varphi_{1}\right) & \cdots & \left(\varphi_{0}, \varphi_{n}\right) \\
\left(\varphi_{1}, \varphi_{0}\right) & \left(\varphi_{1}, \varphi_{1}\right) & \cdots & \left(\varphi_{1}, \varphi_{n}\right) \\
\ldots & \cdots & \ddots & \cdots \\
\left(\varphi_{n}, \varphi_{0}\right) & \left(\varphi_{n}, \varphi_{1}\right) & \cdots & \left(\varphi_{n}, \varphi_{n}\right)
\end{array}\right)\left(\begin{array}{c}
a_{0} \\
a_{1} \\
\cdots \\
a_{n}
\end{array}\right)=\left(\begin{array}{c}
\left(\varphi_{0}, f\right) \\
\left(\varphi_{1}, f\right) \\
\ldots \\
\left(\varphi_{n}, f\right)
\end{array}\right)
$$

\subsubsection{Test fitting result and error analysis}

By studying the relationship between the gray value of the image and the instantaneous voltage in the vicinity of the weld pool in the $\mathrm{CO}_{2}$ welding process, the relationship between the arc and the instantaneous voltage is depicted, and the possibility of the noise produced by the splash metal is also studied. Thus we can express there is or no arc and intensity change through the change of instantaneous voltage in order to get a better quality of the image to do the preliminary preparation. After a lot of experiments, this paper chooses $\mathrm{CO}_{2}$ as the protective gas. Gas flow $10 \mathrm{~L} / \mathrm{min}$. Stainless steel wire diameter $1.2 \mathrm{~mm}$. The length of welding wire is $10 \mathrm{~mm}$. Welding base material is low carbon steel. Welding speed is $550 \mathrm{~mm} / \mathrm{min}$. According to a large number of test cases, the center wavelength of narrow band filter used in this experiment is $550 \mathrm{~nm}$.Welding voltage is $21 \mathrm{~V}$.Camera exposure time is $1.8 \mathrm{~ms}$. Welding current is 140A.Using the above data as the basic parameters to extract the gray value of the image and the instantaneous voltage data.

Based on the image and instantaneous voltage value of the welding process in the welding process of the machine vision acquisition system, the instantaneous voltage data of the 5 groups during the welding process are selected as table 1.Table 1 of each set of data represents a welding cycle phase short circuit instantaneous voltage value, in the process of short circuit welding, grew up as the drop and parent metal contact area is more and more big, the instantaneous current also increases gradually, but instantaneous voltage decreases. Therefore, the instantaneous voltage data of each group in Table 1 is gradually reduced.

Table 1 Instantaneous voltage of short circuit and average gray value of image

\begin{tabular}{lllllll}
\hline $\begin{array}{l}\text { The first } \\
\text { group }\end{array}$ & $\begin{array}{l}\text { The second } \\
\text { group }\end{array}$ & $\begin{array}{l}\text { The third } \\
\text { group }\end{array}$ & $\begin{array}{l}\text { The fourth } \\
\text { group }\end{array}$ & $\begin{array}{l}\text { The fifth } \\
\text { group }\end{array}$ & $\begin{array}{l}\text { The average } \\
\text { voltage } \\
\text { value(V) }\end{array}$ & $\begin{array}{l}\text { The average } \\
\text { gray value }\end{array}$ \\
\hline 25.0517 & 41.0402 & 25.6308 & 24.4018 & 23.4854 & 27.92198 & 25.08952 \\
24.4742 & 31.552 & 25.0188 & 24.1435 & 21.7382 & 25.38534 & 24.04974 \\
22.9063 & 29.8624 & 24.5302 & 23.0313 & 21.0127 & 24.26858 & 24.29794 \\
22.0491 & 21.5062 & 24.1978 & 22.5115 & 20.1127 & 22.07546 & 23.54242 \\
4.3268 & 2.4233 & 2.4825 & 4.539 & 2.6438 & 3.28308 & 24.4119 \\
\hline
\end{tabular}


The instantaneous voltage value and the average value of the image gray value are collected in Table 1,which is fitted by the least square method, and the fitting curve equation of instantaneous voltage and average gray value in short circuit is obtained:

$$
y=0.00016 x^{3}+0.0031 x^{2}-0.21 x+25
$$

Discovered by the fitting results derivative: derived function constant is greater than zero. It shows that the average gray value of the image in the vicinity of the weld pool is decreased with the decrease of the instantaneous voltage at the short circuit stage. This is because with the decrease of the arc voltage and arc length shorter, arc weakened. At this time droplet most has the transition to the parent material, little spatter and gray value decreases. In order to test whether the fitting function satisfies the request, the instantaneous voltage data of 5 sets of short circuit transient process are randomly selected, and the error analysis is carried out in Table 2.

\begin{tabular}{lllll} 
Table 2 Short circuit phase error inspection \\
\cline { 2 - 5 } $\begin{array}{l}\text { Serial } \\
\text { number }\end{array}$ & $\begin{array}{l}\text { Instantaneous } \\
\text { voltage value } \\
(\mathrm{V})\end{array}$ & $\begin{array}{l}\text { Actual gray } \\
\text { value }\end{array}$ & $\begin{array}{l}\text { Fitting gray } \\
\text { value }\end{array}$ & Relative error \\
\hline 1 & 4.9339 & 23.0381 & 24.0586 & $4.43 \%$ \\
2 & 13.0695 & 22.2902 & 23.1421 & $3.82 \%$ \\
3 & 19.0499 & 23.2488 & 23.2306 & $0.078 \%$ \\
4 & 24.0349 & 25.1680 & 23.9650 & $4.78 \%$ \\
5 & 26.1375 & 24.5835 & 24.4860 & $0.4 \%$ \\
\hline
\end{tabular}

The relative error $=($ Fitting value-The actual value/Actual value $)$.According to table 2 error calculation results show that the fitting results and the actual results of the error range are not more than 5\%,which shows that the fitting accuracy is higher.

The average gray value and instantaneous voltage value of the image in the vicinity of the weld pool during the welding process are collected by the machine vision acquisition system. During the welding process, the instantaneous voltage data of 5 open circuit phases are shown in Table 3.Table 3 for each set of data represents the instantaneous voltage value of an open circuit phase. In welding open phase, due to the short circuit at the end of the droplet neck break, the welding current is the largest, subsequent current gradually decreases, and the arc voltage increase gradually. Therefore, the instantaneous voltage of each group in Table 3 is gradually increased. 
Table 3 Instantaneous voltage of open circuit and average gray value of image

\begin{tabular}{lllllll}
\hline $\begin{array}{l}\text { The first } \\
\text { group }\end{array}$ & $\begin{array}{l}\text { The second } \\
\text { group }\end{array}$ & $\begin{array}{l}\text { The third } \\
\text { group }\end{array}$ & $\begin{array}{l}\text { The fourth } \\
\text { group }\end{array}$ & $\begin{array}{l}\text { The fifth } \\
\text { group }\end{array}$ & $\begin{array}{l}\text { The average } \\
\text { voltage } \\
\text { value(V) }\end{array}$ & $\begin{array}{l}\text { The average } \\
\text { gray value }\end{array}$ \\
\hline 1.8952 & 1.7718 & 2.6438 & 2.7951 & 3.3907 & 2.4993 & 23.8590 \\
4.4157 & 5.8552 & 4.8747 & 4.7776 & 5.0820 & 5.0010 & 25.0365 \\
6.1201 & 7.5531 & 10.5655 & 12.3242 & 7.9134 & 8.8953 & 24.2144 \\
7.8821 & 13.4989 & 21.5737 & 22.2548 & 24.9546 & 18.0328 & 23.7471 \\
21.4486 & 29.1023 & 23.4065 & 23.1136 & 26.2313 & 24.6605 & 25.4190 \\
\hline
\end{tabular}

The instantaneous voltage value and the average value of the image gray value are collected in Table 1, which is fitted by the least square method, and the fitting curve equation of instantaneous voltage and average gray value in open circuit is obtained:

$$
y=0.0016 x^{3}-0.057 x^{2}+0.55 x+23
$$

Found that by the fitting results derivative is derived function has two root, $6.7708 \mathrm{~V}$ and $12.3854 \mathrm{~V}$ respectively. In the open circuit stage when the instantaneous voltage is less than $6.7708 \mathrm{~V}$, due to the short circuit just ended, so the arc voltage is very small, arc length growth slow. At the same time, the droplet begins to form, and the radiation near the weld pool becomes larger, so the average gray value of the image captured by the CCD camera of the area near the weld pool is increased with the increase of the instantaneous voltage. When the instantaneous voltage is between $6.7708 \mathrm{~V}$ and $12.3854 \mathrm{~V}$. With the increase of the arc voltage and the droplet volume becomes greatly, which leads to the arc length corresponding to shorter. But electric arc light radiation intensity is far greater than the droplet produced by thermal radiation, so at this stage with the increase of the instantaneous voltage, CCD camera to acquire the molten pool area in the vicinity of the image of the average gray value decreases. When the instantaneous voltage is greater than the $12.3854 \mathrm{~V}$, the droplet volume increases, and the parent metal distance is very short, arc length of arc column can be ignored, molten pool area mainly by molten drops of radiation, so with the increase of the instantaneous voltage, CCD camera to acquire the molten pool area in the vicinity of the image of the average gray value increases.

In order to test whether the fitting function satisfies the request, the instantaneous voltage data of 5 sets of open circuit transient process are randomly selected,and the error analysis is carried out in Table 4. 
Table 4 Open circuit phase error inspection

\begin{tabular}{|c|c|c|c|c|}
\hline Serial number & $\begin{array}{l}\text { Instantaneous voltage } \\
\text { value }(\mathrm{V})\end{array}$ & Actual $g_{1}$ & eFitting gray value & Relative error \\
\hline 1 & 4.6394 & 24.7831 & 24.4846 & $1.2 \%$ \\
\hline 2 & 6.1744 & 23.9819 & 24.5995 & $2.58 \%$ \\
\hline 3 & 10.3039 & 23.6600 & 24.3658 & $2.98 \%$ \\
\hline 4 & 20.7593 & 24.6893 & 24.1675 & $2.11 \%$ \\
\hline 5 & 25.2327 & 25.3135 & 26.2913 & $3.86 \%$ \\
\hline
\end{tabular}

According to table 4 error calculation results show that the fitting results and the actual results of the error range are not more than 5\%, which shows that the fitting accuracy is higher.

\section{Conclusions}

(1)The image acquisition system is established, and the average gray value of the image and the instantaneous voltage of the weld pool are established by the least square method.

(2)In the short circuit phase, with the decrease of the instantaneous voltage, image average gray value decreases. At the open circuit stage, instantaneous voltage is greater than $12.3854 \mathrm{~V}$, with the increase of voltage, increasing average gray value of image; when the instantaneous voltage between $6.7708 \mathrm{~V}$ to $12.3854 \mathrm{~V}$, as the voltage increases, the average gray value of the image is reduced; when the instantaneous voltage is less than $6.7708 \mathrm{~V}$, with the increase of voltage, increasing average gray value of image.

(3)Through the error analysis of the experiment, the mathematical model of the image gray value and instantaneous voltage can meet the objective variation law.

\section{Acknowledgement}

This research was financially supported by the Guangxi Natural Science Foundation (2014GXNSFAA118310).

\section{References}

[1]. Chen-Shu ZHANG, Jian-Xiong YE. Application of ultrasonic wave in seam tracking[J].Welding Technology,2009, 38(4):1-3.(In Chinese)

[2]. Cheng-Hua ZHU, Xian-Guo XU, Zong-Xiang YAO.CO2 gas shielded welding droplet short-circuit transition characteristics research present situation and prospect[J].Electric Welding Machine.2004, 34(12):48-51.(In Chinese)

[3]. Sheng-Tong YANG. Application of $\mathrm{CO} 2$ gas shielded arc welding in automobile body welding[J].Equipment Manufacturing 
Technology ,2009(2):147-149.(In Chinese)

[4]. Zhi-Gui CHENG, Li-Ming YANG, Xian-Zhong WU. Application of CO2 gas shielded arc welding in the case of condenser[J].Modern Welding Technology, 2010(5):80-82.(In Chinese)

[5]. Xiao-Gang LIU. Research on the key technology of seam tracking of intelligent arc welding robot visual servo based on arc surface reflection[D].South China University of Technology,2009.(In Chinese)

[6]. Jun-Bo WANG.A wall climbing robot key technology of automatic welding line tract function[D].Tsinghua University,2002.(In Chinese)

[7]. Xiang-Bing ZHAO, Liang-Yu LI, Chang-Liang XIA. Image processing of laser vision seam tracking system[J].Transactions of the China Welding Institution, 2006, 27(12):42-44.(In Chinese)

[8]. Qiang Chen, Zhen-Guo Sun. Application of computer vision sensing technology in welding[J].Transactions of the China Welding Institution, 2001, 22(1):83-90.(In Chinese)

[9]. H Van de Vel. The Haar condition and multiplicity of zeros [J]. Numerische Mathematik, 1982, 39(1):139-153. 